\section{ATMOSPHERIC POLLUTION.}

$A 5$ recorded in NaTuRE of December 17 , r9i4 (vol. $\mathrm{A}^{\mathrm{s}}$ xciv., p. 433 ), Sheffield is one of the cities joining in the observations on atmospheric pollution

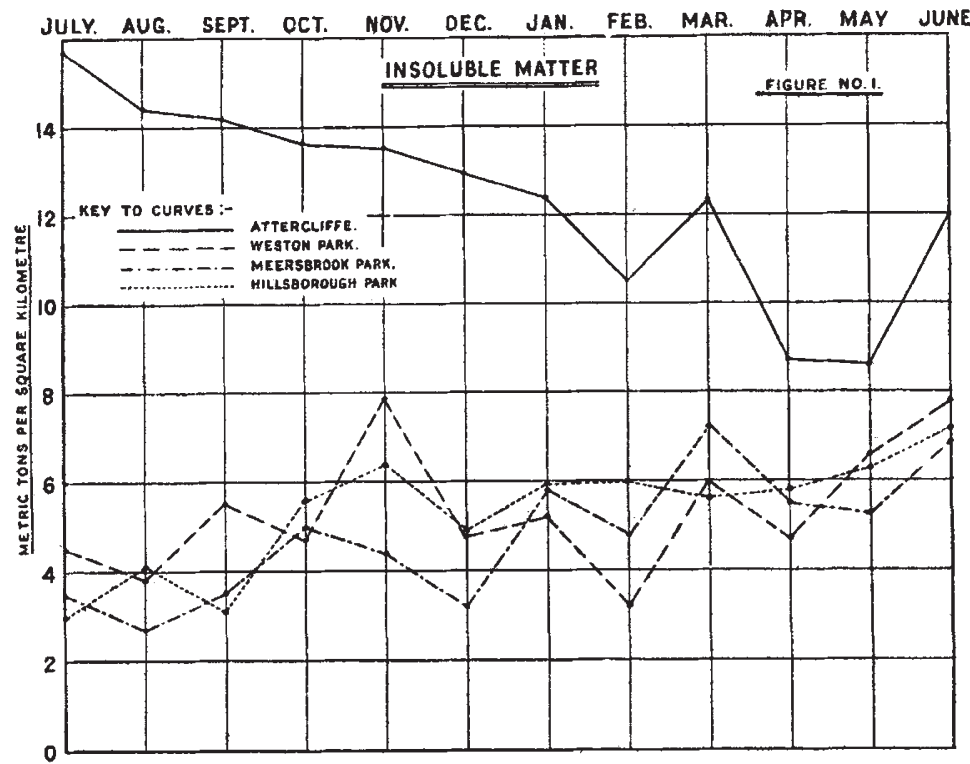

The curves, which show the total amount of insoluble matter (Fig. I), and the total dissolved matter (Fig. 2) found in the rain-water collected at the end of each month, indicate for the three parlss some deterioration of the atmosphere, as might be expected from the abnormal conditions arising out of the war. But the unmistakable evidence of diminishing pollution which the Attercliffe curves suggest, finds no support from what is known about the difficulties encountered in the east end with plant on war material contracts pushed to its utmost capacity, with fuel, and with the shortage of competent firemen, and it is in conflict with the sunshine records for Attercliffe, which show no improvement when compared with the average of the preceding ten years, ${ }^{3}$ and with the number of warnings about excessive smoke emission issued by the smoke inspector, which show no decrease when compared with the average of the two preceding years."

The total amount of each constits. ent determined in the rain-water col. lected at the four sites during the period July $\mathrm{r}$, I9I4, to June 30, I9I5, is set out in metric tons per square kilometre in the table:- arranged by a committee representative of the Smoke Abatement Societies of the United Kingdom. The monthly results of the chemical examination of rainwater collected at four sites, approximately N., S., E., and W. of the Town Hall, ${ }^{2}$ have been published in the Lancet, and are being embodied in the annual report of the medical officer of health of the city of Sheffield. The results do not accord with expectation, and certain conclusions have been reached which are perhaps of more than local interest, as they throw doubt on the value of chemical analyses of rain-water, either in the investigation of atmospheric pollution or in a comparison of the extent of pollution in different localities. It should be borne in mind that in Sheffield the distinction between factory and domestic smoke, which is based on the relative amounts of tarry matter and ammonia in the atmosphere (this journal, loc. cit.), cannot be drawn owing to the large number of reheating and annealing furnaces in operation in the east end (where the large steel works are situated), for which coal is burned so as to produce the smoke necessary for the metallurgical processes involved.

1 Communicated in abstract to Section B(Chemistry) of the British As:ociation, at Manchester, on September 9,1915 , and abridged from a Report made to the Health Committee of the Sheffield City Council in Septemher, ror 5 , by Prof. W. P. Wyrne, F.R.S. The whole $r f$ the chemical analises were made by Mr. Percy Hall-r, who was also responsible for the collection of the rain-water from the gauges. 2 Attercliffe (Don valley), gauge approximately sea-level; Hillsborough Park (Don valley), gauge approximately 2 miles N.N.W. of Town Hall and $250 \mathrm{ft}$. above sea-level; Meersbrook Park (Ruskin Museum), gauge approximately 2 miles S. of Town Hall and (Ruskin Museum), gauge approximately 2 miles $\mathrm{S}$. of $362 \mathrm{ft}$. above Sea-level; Weston Park (University), gauge approximately placed on the ground-level and at a sufficient distance from buildings to render the results comparative.

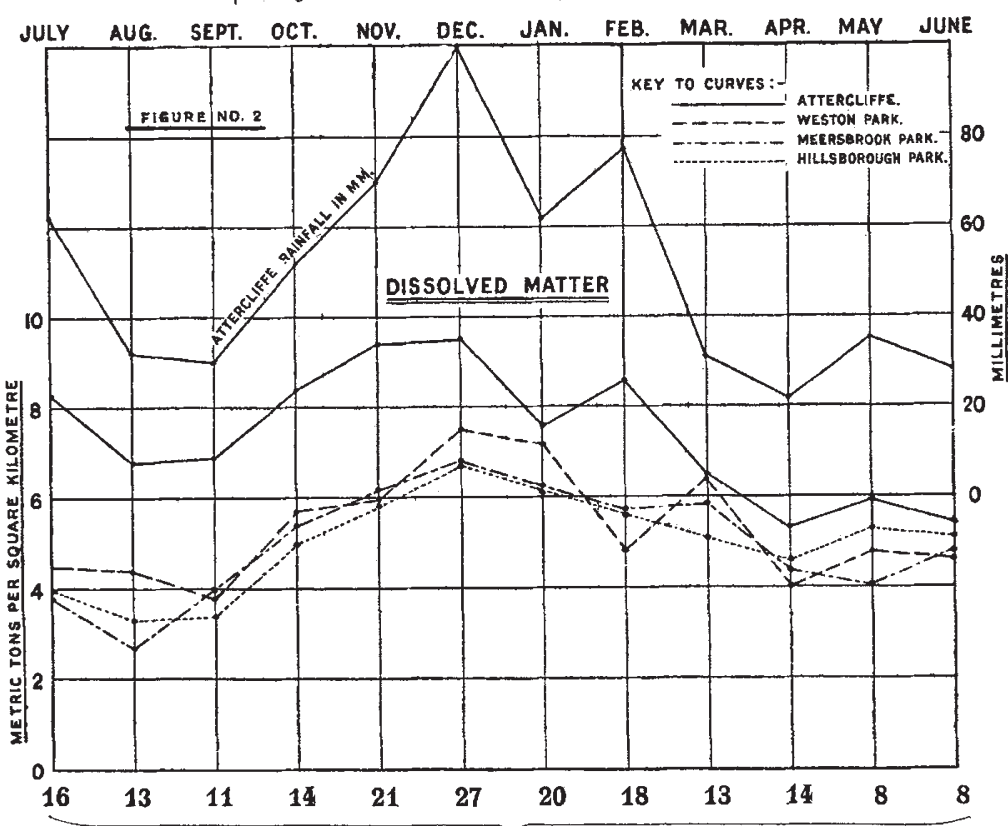

No. of days in each month on which rain fell in Sheffield.

3 Mr. E. Howarth, Curator of Weston Park Museum, has supplied the following information: Bright: sunshine rezistered at Attercliffe during period July Weston Park 1914 , to Jun iaverage 1322 hours); at Bournemouth, 179 i hour (average 1740 hours).

(average 1740 hours). period July $\mathrm{x}, \mathrm{x} 9 \mathrm{I} 4$, to June 30 , $19 \mathrm{I}_{5}$, they were $25 \mathrm{I}$. NO. 2407 . VOL. 067 
From these figures it will be seen that, while the amount of suspended combustible matter (carbon and tar) and mineral matter in the Attercliffe atmosphere is from 2.5 to 3 times as great as in that of the other districts, that of dissolved matter is not more than I. 5 times as great.

These figures furnish no clue to the amount of impurity in the atmosphere, except when rain is falling; nor is it clear to what extent allowance must be made for the amount of soluble matter dissolved by the same volume of rain when it falls in large drops and rapidly in one district but slowly and in a finely divided state in another. At the best, they represent a minimum value; they take no account of pollution during rainless periods, and to convey an approximate idea of the foulness of town atmospheres each monthly result would need to be multiplied by some factor derived from the proportion of rainless to rainy periods in the month. It is doubtful, therefore, whether a comparison of results obtained at different stations in the same observing area, or from different towns, under the Organising Committce's scheme of rain-water investigation, can have much value until in the Lancet to the end of September, I9 ${ }_{5}$, are given in the following table:-

\begin{tabular}{|c|c|c|c|c|c|c|c|c|c|c|}
\hline & Jily & Aug. & Sept. & Oct. & Nov. & Dec & Jan. & Feb. & Mar. & April \\
\hline Jar . . . & o*or & $0: 01$ & $0^{\circ} 01$ & nil. & 0.01 & 0.01 & trace & - & $\ldots$ & \\
\hline Insoluble matter & 0.71 & 0.71 & $0.8 \mathrm{r}$ & 242 & $\begin{array}{l}0.1 \\
0.46\end{array}$ & $\begin{array}{ll}1 \\
0\end{array}$ & $\begin{array}{l}0.12 \\
0.12\end{array}$ & 0.25 & $0: 2 I$ & 7 \\
\hline Hissolved . . & $r * 76$ & $x \cdot 30$ & $0: 72$ & I. 29 & I.92 & 2.54 & I.93 & $I^{\circ} 47$ & $08 \mathrm{r}$ & 0.8 \\
\hline Total sulids & 247 & $20 \mathrm{OI}$ & $\therefore .53$ & 172 & $2 \cdot 3^{8}$ & 3.39 & $2 \cdot 06$ & 172 & $I^{\circ} 02$ & I.07 \\
\hline Sulphate $\left(\mathrm{SO}_{4}\right)$ & 0.56 & 0.47 & 0.18 & 043 & 0.53 & 0.79 & 0.7 .4 & $0_{4 I}$ & 0.28 & 0.25 \\
\hline e (Cl) & $\therefore 35$ & 0.13 & $0^{\circ} 12$ & 0.19 & 036 & 0.56 & 0.24 & $0.4 \tau$ & 0.10 & OII \\
\hline Amr & 0.05 & 0.03 & 0.00 & 0.02 & o:o: & 002 & 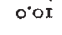 & $0.0 x$ & $0.0 x$ & 0.12 \\
\hline Rainfall in $\mathrm{mm}$. & 80 & 36 & 22 & $3^{6}$ & $6 x$ & 80 & 64 & 57 & I9 & 17 \\
\hline
\end{tabular}

While the figures recorded for insoluble matter, including tar, are not easy to interpret, those for dissolved solids and for sulphate seem at first sight to indicate an increase in pollution with the advent of winter. But they bear another complexion when plotted against the measured monthly rainfall, as will be clear from an inspection of diagram No. 3, and the criticism may be ventured that, for a town like Malvern, the Organising Committee's scheme of chemical investigation might serve better as a means of recording variations in rainfall than as a method for determining the extent of variation of atmospheric pollution. Nor is this criticism disarmed in the case of a manufacturing town like Sheffield, in which atmospheric pollution is due partly to industrial smokefairly constant in amount all the year round-and to domestic smoke, varying in amount according to the season, for when a comparison is made of the curves for the rainfall and for the dissolved solids and the sulphate, a similar correspondence in shape can be traced. As an illustration, the Attercliffe rainfall curve is shown in Fig. 2 above the curve for dissolved matter for the same district.

It seems probable that the chemical investigation of atmospheric pollution by the rain-water method could give comparative results only if rain fell at a unform rate, and either all day or at the same period of each day, conditions something is known of the extent to which the data are dependent on the duration of the rain per month, or on the number of days on which rain was collected, or on the rate at which the rain came down, or on the direction and velocity of the wind during the dry and wet periods in the month.

Of all these influences which affect any scientific interpretation of the rain-water data, the only one that can be tested is the rainfall per month. To ascertain the influence which monthly variations in the rainfall may exercise on the amount of impurities washed out from the atmosphere by the falling rain, it is desirable to select the case of a town like Malvern, which is practically free from industrial smoke. As the pollution of Malvern's atmosphere may be assigned to one source-household fires-it might be expected to increase with the seasonal fall in temperature: to be greater in the winter than in the summer months. The figures (metric tons per square kilometre) for the period July I, I9I4, to April 30 , I $9 I_{5}{ }^{5}$ as published

- The Malvern results for May and June, which have since been published (Lancet, October 9, p. 822 ; November 6, p. 1046), support the conclusions drawn from the earlier data. not attainable in nature. Notoriously, Sheffield's atmosphere is at its worst on a calm day; there were many days during last winter when the University building, $250 \mathrm{ft}$. above the Don valley, was enveloped in a smoke fog, but as no rain fell the pollution of the atmosphere, so evident to the senses, found no record in the chemical analyses of the rain-water collected on other days than these. Better results might be obtained if a feasible method could be devised for drawing air continuously and at a given rate through water, but whether their value, as evidence of atmospheric pollution, would be commensurate with the cost is a question which experiment alone could decide. If the British Association could see its way to appoint a committee to investigate the comparative merits of chemical and physical methods of studying atmospheric pollution, ${ }^{6}$ new processes might be devised which would furnish evidence of avoidable pollution (the main object of the inquiry into the smoke nuisance) more readily and at less cost than the chemical analysis of water used to wash impurity out of the air.

6. Since this paper was read, a committee of the British Association has been appointed to report on "Fuel Economy and Smoke Abatement" (see p. 205.) 
Subject to the limitations imposed on any comparative treatment of the results recorded for the towns which have taken part in the inquiry, it may be of interest to point out that, after allowances have been made for differences in rainfall, Sheffield, according to the analytical data published in the Lancet, is a less smoky city than Manchester. This conclusion follows from a comparison of the figures for the six stations, N., E., and S., situated within three miles of Manchester Town Hall (Salford, on the west, did not take part in the inquiry), with those for the four stations, roughly, N., E., S., and W., situated within two miles of the Sheffield Town Hall. How far such evidence justifies the conclusion that Manchester chimneys pour into its atmosphere a correspondingly larger amount of impurity is doubtful; the contour of the land as promoting or retarding the dispersal of smoke is one of many factors to be taken into account before a definite opinion should be hazarded, and no two towns could differ more than Manchester and Sheffield in this respect.

\section{UNIVERSITY AND EDUCATIONAL INTELLIGENCE.}

Ir is stated in the issue of Science for November 26 that approximately $200,000 l$. is to go to Yale University under the will of the late $\mathrm{Mr}$. Justus $\mathrm{S}$. Hotchkiss, of New Haven. The trust fund thus established is to be shared equally among the academic, law, and theological departments.

THE Cambridge University Press has published "The Book of Matriculations and Degrees : a Catalogue of those who have been matriculated or admitted to any Degree in the University of Cambridge from IgOI to Ig12." With the present volume the period covered, so far as a record of degrees is concerned, is from I544 to I9I2. Honorary titles of degrees conferred from Igor to IgI2 are included. The catalogue has been prepared for the press by Mr. B. Benham, the assistant registrary, and $\mathrm{Mr}$. C. J. Stonebridge, the registrary's clerk. 'The price of the volume is I2s. $6 d$. net.

DR. JOHN READ, lecturer and demonstrator in chemistry in the University of Cambridge, has been elected to the chair of organic chemistry-pure and appliedin the University of Sydney, in succession to Prof. R. Robinson, lately appointed to the chair of organic chemistry at Liverpool. Dr. Read was educated at Sexey's School, Bruton, Somerset, passed through the Finsbury Technical College, under Prof. R. Meldola, in I90I-I904, was at Zürich with Prof. Alfred Werner, I905-7, and has since been associated with Prof. W. J. Pope at Manchester and Cambridge, having published in collaboration with him a considerable number of papers of stereochemical interest.

THE sixteenth annual meeting of the Association of Public School Science Masters will be held on January 4 and 5, under the presidency of Sir William Osler, who will open the proceedings with an address entitled "The Fateful Years, 1915-1917," in which he will make a plea for earlier and more intensive work in science subjects so as to save time at the universities. The programme also includes the following papers and subjects for discussion:- "Desirability of Giving a Bias towards Agriculture in the Science Teaching in Schools," C. Turnor; "School Museums," M. D. Hill ; "War-Work in Schools," S. J. Hough; "The Extent to which it is Desirable to Modify the Teaching of Science in Schools to Meet the Requirements of War." C. L. Bryant.

Dr. E. Fox Nichols has resigned the presidency of Dartmouth College, New Hampshire, which he has held since 1909, in order to accept an invitation to a chair of physics at Yale. In his letter to the Dartmouth trustees he explains that the special needs of the college which led him to accept the headship have now been largely met, and that there seems therefore no compelling reason why he should not go back to his earlier work, the duties and recompenses of which are in fuller accord with his individual taste and preference. The incident has aroused a good deal of favourable comment in the American Press, as indicating a break in the general tendency, in American academic circles, to prefer the attractions of an administrative post to the claims of scientific research and teaching.

THE approaching retirement of Dr. William Garnett from the post of educational adviser to the London County Council demands some grateful reference to years of work that have left a permanent mark upon London education. A student of the Royal School of Mines and a Whitworth scholar, a fellow of St. John's and first demonstrator under Clerk Maxwell in the Cavendish Laboratory, Dr. Garnett illustrated in his training the happy union between pure and applied science upon which the well-being, and even the security, of our national life depend. His principalship of the Durham College of Science showed how clearly he had grasped the essential principles of technical education; his opportunity of applying those principles on a large scale came with his appointment, in 1893, as secretary and educational adviser to the Technical Education Board of the London County Council. The eleven years of the board's activity must always be regarded as of momentous importance in the history of London education. Polytechnics sprang into being or were revivified, a clearly conceived system of central and local technical institutes materialised, the conditions of science teaching in secondary schools were enormously improved, and the scientific and technical work of the University was greatly stimulated and aided. The hand of Dr. Garnett was plainly visible in all these good works, and they will be his enduring monument.

\section{SOCIETIES AND ACADEMIES. LONDON.}

Physical Society, November 26.--Dr. A. Russell, vicepresident, in the chair.-J. Guild: Obtaining and maintaining a bright hydrogen spectrum, with special reference to the 434 I line. The paper treats of the conditions of pressure, discharge, etc., most suitable for the production of a bright hydrogen spectrum, such as is required for refractometry and similar purposes. The rapid deterioration of the tubes with use is shown to be caused by a rise of pressure due to the evolution of hydrogen by the electrodes. The trouble may be obviated by sealing an auxiliary bulb of $1 \frac{1}{2}$ or 2 litres capacity to the discharge tube. This reduces the rate of pressure variation and prolongs the useful life of the tube nearly a hundredfold. The use of capacity and inductance is shown to be very helpful with partially deteriorated tubes.-A. Griffiths, J. M. Dickson, and C. H. Griffitls : The determination of the coefficient of diffusion of potassium chloride by an analytical method. This paper represents an attempt to develop an analytical method of determining the coefficient of diffusion of a salt in water capable of giving consistent and accurate results. The lower ends of a number of vertical and parallel diffusion tubes terminate in a reservoir of large capacity containing a solution of potassium chloride. The greater part of the reservoir is above the lower ends of the tubes, and by gravity the solution at the lower ends is kept at an approximately constant concentration. The upper

NO. 2407 , VOL. 96] 